TITLE:

\title{
Vacuum ultraviolet
} photodissociation and surface morphology change of water ice films dosed with hydrogen chloride

\section{$\operatorname{AUTHOR}(\mathrm{S}):$}

Yabushita, A; Kanda, D; Kawanaka, N; Kawasaki, M

\section{CITATION:}

Yabushita, A ...[et al]. Vacuum ultraviolet photodissociation and surface morphology change of water ice films dosed with hydrogen chloride. JOURNAL OF CHEMICAL PHYSICS 2007, 127(15): 154721.

ISSUE DATE:

2007-10-21

URL:

http://hdl.handle.net/2433/50144

\section{RIGHT:}

Copyright 2007 American Institute of Physics. This article may be downloaded for personal use only. Any other use requires prior permission of the author and the American Institute of Physics. 


\title{
Vacuum ultraviolet photodissociation and surface morphology change of water ice films dosed with hydrogen chloride
}

\author{
Akihiro Yabushita, Daichi Kanda, Noboru Kawanaka, and Masahiro Kawasaki ${ }^{\text {a) }}$ \\ Department of Molecular Engineering, Kyoto University, Kyoto 615-8510, Japan
}

(Received 6 March 2007; accepted 12 September 2007; published online 19 October 2007)

\begin{abstract}
Time-of-flight (TOF) spectra of photofragment $\mathrm{H}$ atoms from the photodissociation of water ice films at $193 \mathrm{~nm}$ were measured for amorphous and polycrystalline water ice films with and without dosing of hydrogen chloride at $100-145 \mathrm{~K}$. The TOF spectrum is sensitive to the surface morphology of the water ice film because the origin of the $\mathrm{H}$ atom is the photodissociation of dimerlike water molecules attached to the ice film surfaces. Adsorption of $\mathrm{HCl}$ on a polycrystalline ice film was found to induce formation of disorder regions on the ice film surface at 100-140 K, while the microstructure of the ice surface stayed of polycrystalline at $145 \mathrm{~K}$ with adsorption of $\mathrm{HCl}$. The TOF spectra of photofragment $\mathrm{Cl}$ atoms from the $157 \mathrm{~nm}$ photodissociation of neutral $\mathrm{HCl}$ adsorbed on water ice films at $100-140 \mathrm{~K}$ were measured. These results suggest partial dissolution of $\mathrm{HCl}$ on the ice film surface at 100-140 K. () 2007 American Institute of Physics.
\end{abstract}

[DOI: $10.1063 / 1.2794342]$

\section{INTRODUCTION}

There has been a widespread interest in characterizing $\mathrm{HCl}$ adsorption at the ice surface and probing the morphology change by adsorption of $\mathrm{HCl}$ on water ice surfaces because morphology may have a significant effect on the reactivity of ice films. ${ }^{1}$ Adsorption, desorption, surface mobility, and bulk diffusion of reagents and reaction products may depend on the ice microstructure because pores facilitate trapping of large quantities of gases in the bulk of amorphous ice films, and a high density of surface defects leads to an increase in the hydrogen bonding abilities of crystalline ice films. However, conventional spectroscopic techniques probe both surface and bulk phases except for a technique using atom collisions. Hence, a new technique is required to investigate effects of adsorption of molecules on the morphology of ice films.

In our previous experiments, we have shown that hydrogen atoms are produced as primary photoproducts when dimerlike water molecules on the outermost layer of a polycrystalline ice film are dissociated at $193 \mathrm{~nm}$ based on the fact that the photoabsorption of the branched water cluster is redshifted compared with that of cyclic water clusters. ${ }^{2}$

$$
\mathrm{H}_{2} \mathrm{O}-\left(\mathrm{H}_{2} \mathrm{O}\right)_{n}+h \nu(193 \mathrm{~nm}) \rightarrow \mathrm{H}+\mathrm{HO}-\left(\mathrm{H}_{2} \mathrm{O}\right)_{n} \text {. }
$$

In the $193 \mathrm{~nm}$ photodissociation of a crystalline ice film, the time-of-flight (TOF) spectra of the $\mathrm{H}$ atoms consisted solely of a fast component of the Maxwell-Boltzmann energy distribution. However, a slow component became dominant from an amorphous ice film due to the collisional relaxation process of the photofragment $\mathrm{H}$ atoms in the micropores on the surface. Thus, if the ice surface morphology is distorted by dosing with $\mathrm{HCl}$, a change in the TOF spectrum of the $\mathrm{H}$ atoms is expected. This TOF technique could be a sensitive

\footnotetext{
${ }^{\text {a) }}$ Author to whom correspondence should be addressed. FAX: +81-75-3832573. Electronic mail: kawasaki@photon.mbox.media.kyoto-u.ac.jp
}

method to investigate the surface morphology change of water ice films.

There are numerous reports of experimental and theoretical studies on the interactions of ice films with $\mathrm{HCl}$. For example, Kang et al. observed the transformation of $\mathrm{HCl}$ adsorbed on ice surfaces from a predominantly molecular form to an ionic species during heating from 50 to $140 \mathrm{~K}^{3}$ In the present study, using the TOF techniques we have studied morphology change of the outermost layer of ice films by dosing with $\mathrm{HCl}$ as a function of temperature. We will compare our results with the previously reported studies on the interaction, and discuss the origins of the $\mathrm{H}$ atoms from the vacuum ultraviolet photodissociation of water ice films dosed with $\mathrm{HCl}$.

\section{EXPERIMENT}

The experimental apparatus and procedures of ice film preparation have been described elsewhere. ${ }^{4}$ Photodissociation of water ice films was carried out in a high vacuum chamber, which was equipped with two turbo molecular pumps in tandem. Ice films were prepared on polycrystalline Au substrates with (111) domains. ${ }^{5}$ Two types of ice films were used in this experiment: amorphous solid water (ASW) and polycrystalline ice (PCI) films. ASW films were prepared with background (backfill) deposition at $100 \mathrm{~K}$ for $60 \mathrm{~min}$. The exposure of water vapor was typically $1800 \mathrm{~L}$ ( $1 \mathrm{~L}=1 \times 10^{-6}$ Torr $\mathrm{s}$ ), which resulted in the formation of $600 \mathrm{ML}$ of $\mathrm{H}_{2} \mathrm{O}$ on the Au substrate. ${ }^{6}$ PCI films were prepared by background deposition of water vapor at $130 \mathrm{~K}$ for $60 \mathrm{~min}$, and then maintained at this temperature for a further $30 \mathrm{~min}$ for annealing purposes.

The gas mixture of $\mathrm{HCl}$ with $\mathrm{N}_{2}$ diluent (4\%) was introduced into the vacuum chamber via direct or background deposition with a pulsed molecular beam. A typical stagnation pressure of a pulsed gas valve for the mixture gas was 40 Torr. The chamber pressure was $5 \times 10^{-8}$ without sample 
molecule injection. This adsorption resulted in the formation of $1 \mathrm{ML}$ of $\mathrm{HCl}$ on the ice film since multilayer formation of $\mathrm{HCl}$ does not occur. ${ }^{7}$ When $\mathrm{HCl}$ was dosed up to a few tens of langmuirs, the signal intensity increased with dose rate up to $2 \mathrm{~L}$, and approached an asymptotic value for $>2 \mathrm{~L}$. The $193 \mathrm{~nm}$ laser light (Lambda Physik, COMPex, ArF) was directed onto the ice film using a series of aluminum mirrors and a prism resulting in an incident fluence of $1 \mathrm{~mJ} \mathrm{~cm}^{-2}$ pulse $^{-1}$. The $157 \mathrm{~nm}$ photolysis beam (Lambda Physik, OPTexPro, $\mathrm{F}_{2}$ ) was introduced directly on the ice surface (fluence $<1 \mathrm{~mJ} \mathrm{~cm}^{-2}$ pulse ${ }^{-1}$ ). Hydrogen atom photofragments were subsequently ionized at a distance of $3 \mathrm{~mm}$ from the substrate surface by $[2+1]$ resonance enhanced multiphoton ionization (REMPI) on the $\mathrm{H}(2 s \leftarrow 1 s)$ transition with a lens $(f=0.10 \mathrm{~m})$ and collected with a small TOF mass spectrometer aligned perpendicular to the ice surface. The requisite radiation at wavelengths $\sim 243.135 \mathrm{~nm}$ was produced by a neodymium-doped yttrium aluminum garnet pumped dye laser (Lambda Physik, SCANmate, $0.2 \mathrm{~mJ} \mathrm{pulse}^{-1}$ at UV) using Coumarin 480 dye, followed by subsequent frequency doubling with $\mathrm{BaB}_{2} \mathrm{O}_{4}$ crystal. Each spectrum is the sum of several spectra measured at different Doppler shifted wavelengths around that required for the REMPI detection. This laser was also used to ionize the photofragment by $(2+1)$ REMPI at $235.336 \mathrm{~nm}$ for $\mathrm{Cl}\left({ }^{2} D_{3 / 2}\right.$ $\left.\leftarrow{ }^{2} P_{3 / 2}\right)$ and $235.205 \mathrm{~nm}$ for $\mathrm{Cl}^{*}\left({ }^{2} P_{1 / 2} \leftarrow{ }^{2} P_{1 / 2}\right)$. For each spin-orbit state, the REMPI intensity $I$ depends both on the quantum state population $N$ and the ionization efficiency $S$. Thus, $I\left(\mathrm{Cl}^{*}\right) / I(\mathrm{Cl})=\left[N\left(\mathrm{Cl}^{*}\right) / N(\mathrm{Cl})\right]\left[S\left(\mathrm{Cl}^{*}\right) / S(\mathrm{Cl})\right]$. The scaling factor, $S\left(\mathrm{Cl}^{*}\right) / S(\mathrm{Cl})$, was reported to be $1.06 \pm 0.17$ by Regan et $\mathrm{ll}^{8}$

TOF spectra of $\mathrm{H}$ atoms were taken as a function of time delay $t$ between photolysis and probe pulses, which correspond to the flight time between the substrate and the detection region. The TOF spectrum was fitted with $S\left(t, a_{i}, T_{i}\right)$, consisting of three flux-weighted Maxwell-Boltzmann (MB) distributions defined by the translational temperature $T_{i}$ and a coefficient $a_{i}$ :

$$
\begin{aligned}
S\left(t, a_{i}, T_{i}\right)= & a_{1} S_{\mathrm{MB}}\left(t, T_{1}\right)+a_{2} S_{\mathrm{MB}}\left(t, T_{2}\right) \\
& +\left(1-a_{1}-a_{2}\right) S_{\mathrm{MB}}\left(t, T_{3}\right), \\
S_{\mathrm{MB}}(t, r)= & r^{3} t^{-4} \exp \left[-m r^{2} /\left(2 k_{\mathrm{B}} T_{\text {trans }} t^{2}\right)\right], \\
P_{\mathrm{MB}}\left(E_{t}\right)= & \left(k_{\mathrm{B}} T_{\text {trans }}\right)^{-2} E_{t} \exp \left[-E_{t} /\left(k_{\mathrm{B}} T_{\text {trans }}\right)\right],
\end{aligned}
$$

where $r$ is a flight length for the photofragment. The MB distribution, $P_{\mathrm{MB}}\left(E_{t}\right)$, as a function of translational energy $E_{t}$ is characterized by the average translational energy, $\left\langle E_{t}\right\rangle$ $=2 k_{\mathrm{B}} T_{\text {trans }}$, where $k_{\mathrm{B}}$ is the Boltzmann constant and $T_{\text {trans }}$ is the translational temperature. Conversion from the energy distribution to the TOF distribution was performed using the Jacobian listed by Zimmermann and Ho.

In order to simulate the obtained TOF spectra of $\mathrm{Cl}$ atoms, we used a composite of normalized TOF functions, $S_{G}(t)$ and $S_{\mathrm{MB}}(t)$. These functions correspond to a Gaussian translational energy distribution, $P_{G}\left(E_{t}\right)$, and a flux-weighted

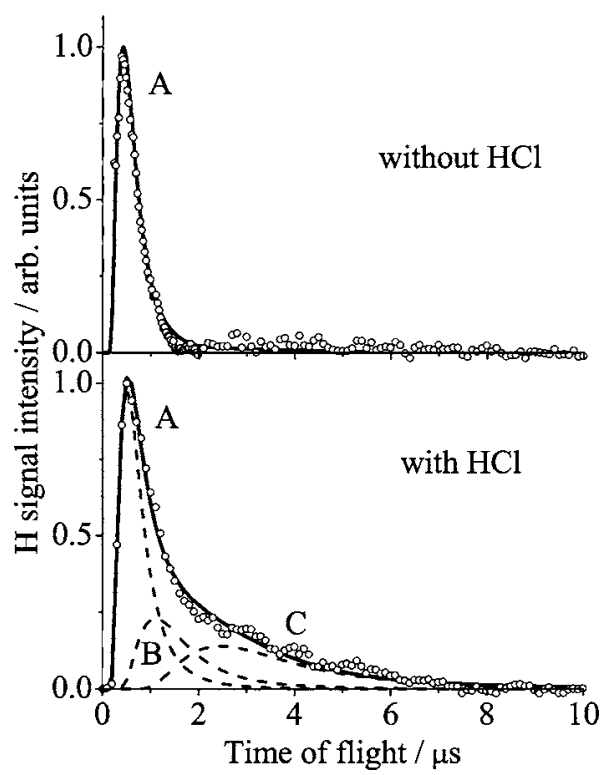

FIG. 1. Time-of-flight spectra of $\mathrm{H}$ atoms from the $193 \mathrm{~nm}$ photodissociation of polycrystalline ice films with and without $\mathrm{HCl}$ (1 ML) at $100 \mathrm{~K}$ (open circles). The solid curves are fits to the data derived assuming a Maxwell-Boltzmann distribution with $T_{\text {trans }}=2400 \mathrm{~K}$ for component A (upper panel), and the sum of three distributions with $T_{\text {trans }}=2400 \mathrm{~K}$ for A, $500 \mathrm{~K}$ for $\mathrm{B}$, and $110 \mathrm{~K}$ for $\mathrm{C}$ (lower panel). Contributions of the Maxwell-Boltzmann components are listed in Table I.

MB energy distribution, $P_{\mathrm{MB}}\left(E_{t}\right)$, respectively. $P_{G}\left(E_{t}\right)$ is characterized by the average energy, $\left\langle E_{t}\right\rangle$, and the energy width $w$.

$$
\begin{aligned}
& S(b, t)=b S_{G}(t)+(1-b) S_{\mathrm{MB}}(t), \\
& P_{G}\left(E_{t}\right)=\left[(2 \pi)^{1 / 2} w\right]^{-1} \exp \left[-2\left(E_{t}-\left\langle E_{t}\right\rangle\right)^{2} / w^{2}\right],
\end{aligned}
$$

where $b$ is a coefficient. The details of simulation of the TOF spectra were described in our previous paper. ${ }^{4}$

\section{RESULTS}

\section{A. Time-of-flight spectra of hydrogen atoms from the photodissociation of water ice films with and without dosing of $\mathrm{HCl}$ at 193 and $157 \mathrm{~nm}$}

Figure 1 shows the TOF spectra of $\mathrm{H}$ atoms from the $193 \mathrm{~nm}$ photodissociation of PCI films with and without dosing of $\mathrm{HCl}(1 \mathrm{ML})$ at $100 \mathrm{~K}$. The TOF spectrum for the ice film without $\mathrm{HCl}$ is well described by the fast component A with $T_{\text {trans }}=2400 \pm 100 \mathrm{~K}\left(\left\langle E_{t}\right\rangle=0.31 \pm 0.01 \mathrm{eV}\right)$. Upon dosing with $\mathrm{HCl}$, additional signals appeared in the TOF spectrum, and the intensity of component A stayed almost the same. The TOF spectrum is reproduced by summing three different MB distributions: the fast component $\mathrm{A}$ with $T_{\text {trans }}$ $=2400 \pm 100 \mathrm{~K}$ contributing $(47 \pm 7) \%$ and the surfaceaccommodated slow component $\mathrm{C}$ with $T_{\text {trans }}=110 \pm 10 \mathrm{~K}$ $(0.01 \mathrm{eV})(32 \pm 10) \%$. The residual TOF signal is approximated by a single $\mathrm{MB}$ distribution, the middle component $\mathrm{B}$ with $T_{\text {trans }}=500 \pm 50 \mathrm{~K}(0.06 \mathrm{eV})(21 \pm 3) \%$. The signal of the $\mathrm{B}$ and $\mathrm{C}$ components appeared even at a dose rate of $0.06 \mathrm{~L}$. Its intensity increased with dose rate up to $2 \mathrm{~L}$, and became an asymptotic value for $>2 \mathrm{~L}$. 


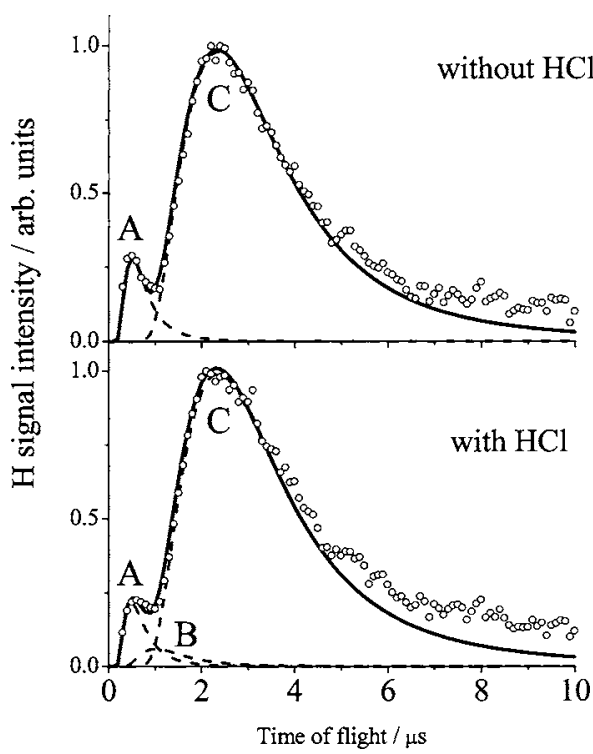

FIG. 2. TOF spectra of $\mathrm{H}$ atoms from the $193 \mathrm{~nm}$ photodissociation of amorphous solid water films with and without $\mathrm{HCl}(1 \mathrm{ML})$ at $100 \mathrm{~K}$. Fits are to three Maxwell-Boltzmann distributions with $T_{\text {trans }}=2400 \mathrm{~K}$ for A, $500 \mathrm{~K}$ for $\mathrm{B}$, and $110 \mathrm{~K}$ for $\mathrm{C}$. Contributions of components $\mathrm{A}, \mathrm{B}$, and $\mathrm{C}$ are listed in Table I.

Figure 2 shows the TOF spectra from the $193 \mathrm{~nm}$ photodissociation of ASW films at $100 \mathrm{~K}$ with and without $\mathrm{HCl}$ (1 ML). Both spectra are similar to each other, and consist mainly of component $\mathrm{C}$. There are very small contributions of components $\mathrm{A}$ and $\mathrm{B}$.

The upper panel of Fig. 3 shows the TOF spectra from

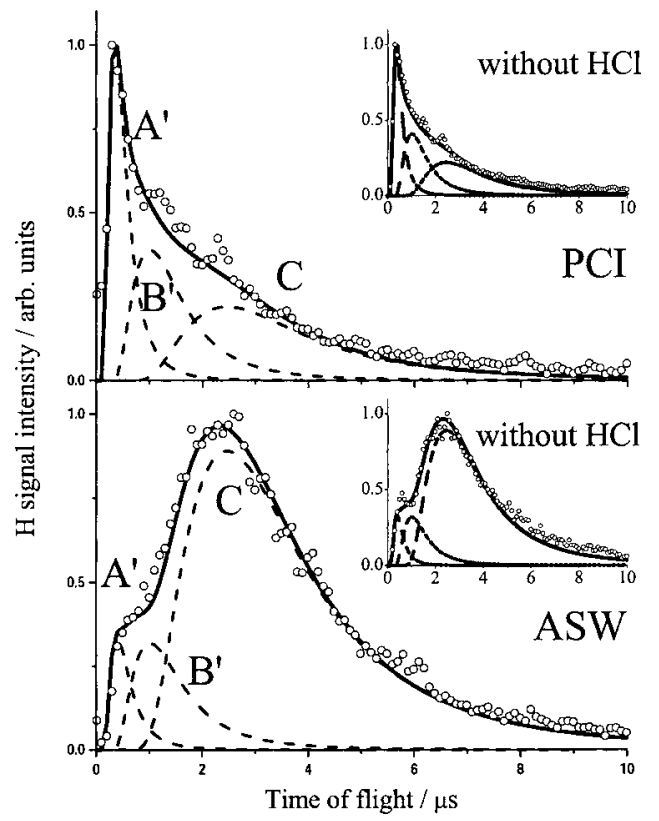

FIG. 3. The upper panel shows TOF spectra of $H$ atoms from the $157 \mathrm{~nm}$ photodissociation of polycrystalline ice (PCI) films with $\mathrm{HCl}(1 \mathrm{ML})$ at $100 \mathrm{~K}$. The inset shows the spectrum without $\mathrm{HCl}$. Fits are to three Maxwell-Boltzmann distributions with $T_{\text {trans }}=4750 \mathrm{~K}$ for A', $625 \mathrm{~K}$ for B', and $110 \mathrm{~K}$ for $\mathrm{C}$. The lower panel shows TOF spectra of $\mathrm{H}$ atoms from the $157 \mathrm{~nm}$ photodissociation of amorphous solid water (ASW) films with $\mathrm{HCl}$ $(1 \mathrm{ML})$ at $100 \mathrm{~K}$. The inset shows the spectrum without $\mathrm{HCl}$. Fits are to three Maxwell-Boltzmann distributions with $T_{\text {trans }}=4750 \mathrm{~K}$ for A' $\mathrm{A}^{\prime}, 625 \mathrm{~K}$ for $\mathrm{B}^{\prime}$, and $110 \mathrm{~K}$ for $\mathrm{C}$. Contributions are listed in Table I. the $157 \mathrm{~nm}$ photodissociation of PCI films at $100 \mathrm{~K}$ with and without $\mathrm{HCl}(1 \mathrm{ML})$. Both spectra are essentially the same. Three MB components, $\mathrm{A}^{\prime}, \mathrm{B}^{\prime}$, and $\mathrm{C}$, are characterized by $T_{\text {trans }}=4750 \pm 250 \mathrm{~K}(0.61 \pm 0.04 \mathrm{eV})$ contributing $(41 \pm 3) \%$, $625 \pm 25 \mathrm{~K}(0.08 \mathrm{eV})(44 \pm 4) \%$, and $110 \pm 10 \mathrm{~K}(0.01 \mathrm{eV})$ $(15 \pm 5) \%$, respectively. The lower panel of Fig. 3 shows the TOF spectra from the $157 \mathrm{~nm}$ photodissociation of ASW films at $100 \mathrm{~K}$ with and without $\mathrm{HCl}(1 \mathrm{ML})$, which are essentially the same, and represented by summing three MB components, $\quad \mathrm{A}^{\prime}[(5 \pm 2) \%], \quad \mathrm{B}^{\prime}[(12 \pm 2) \%], \quad$ and $\mathrm{C}[(83 \pm 4) \%]$. Table I summarizes the contribution and translational temperature of each component.

\section{B. Substrate temperature dependence of the time-of-flight spectra of hydrogen atoms from the $193 \mathrm{~nm}$ photodissociation of polycrystalline ice films dosing with $\mathrm{HCl}$}

Figure 4 shows the substrate temperature dependence of TOF spectra of the $\mathrm{H}$ atoms from the $193 \mathrm{~nm}$ photodissociation of PCI films with $\mathrm{HCl}(1 \mathrm{ML})$. PCI films were prepared and exposed to $\mathrm{HCl}$ at $100 \mathrm{~K}$, and then maintained at four different substrate temperatures, $T_{s}=100,120,140$, and $145 \mathrm{~K}$ for a further $30 \mathrm{~min}$. And then, the substrate temperature was reduced to $100 \mathrm{~K}$ during the TOF measurements. In the obtained TOF spectra, the contributions of components B and $\mathrm{C}$ gradually decreased with $T_{s}$ up to $140 \mathrm{~K}$, and finally disappeared at $145 \mathrm{~K}$. The surface composition of the thusprepared film is not changed by cooling it from 140 to $100 \mathrm{~K}^{10}$

\section{Time-of-flight spectra of chlorine atoms from the photodissociation of molecular $\mathrm{HCl}$ adsorbed on water ice films at $157 \mathrm{~nm}$}

Figure 5 shows the TOF spectra of $\mathrm{Cl}\left({ }^{2} P_{3 / 2}\right)$ and $\mathrm{Cl}^{*}\left({ }^{2} P_{1 / 2}\right)$ atoms from the $157 \mathrm{~nm}$ photodissociation of ASW films dosed with $\mathrm{HCl}(1 \mathrm{ML})$ at $100 \mathrm{~K}$. The TOF spectra are reproduced by a combination of the Gaussian and MB distributions. The Gaussian distribution of $\mathrm{Cl}\left({ }^{2} P_{3 / 2}\right)$ is characterized by $\left\langle E_{t}\right\rangle_{\mathrm{Cl}}=1.4 \pm 0.1 \mathrm{eV}, w_{\mathrm{Cl}}=0.9 \pm 0.1 \mathrm{eV}$ contributing $(2 \pm 1) \%$. The MB distribution is characterized by $T_{\text {trans }}(\mathrm{Cl})$ $=1700 \pm 100 \mathrm{~K}(0.22 \pm 0.01 \mathrm{eV})(98 \pm 1) \%$. For $\mathrm{Cl}^{*},\left\langle E_{t}\right\rangle_{\mathrm{Cl}^{*}}$ is $1.4 \pm 0.1 \mathrm{eV}, w_{\mathrm{Cl}^{*}}=0.9 \pm 0.1 \mathrm{eV}$ contributing $(3 \pm 1) \%$. The MB distribution is characterized by $T_{\text {trans }}\left(\mathrm{Cl}^{*}\right)$ $=2800 \pm 200 \mathrm{~K} \quad(0.36 \pm 0.03 \mathrm{eV})$. The branching ratio, $\left[\mathrm{Cl}^{*}\right] /[\mathrm{Cl}]$, was $0.08 \pm 0.03$.

Figure 6 shows the TOF spectra from the PCI film dosed with $\mathrm{HCl}(1 \mathrm{ML})$ at $100 \mathrm{~K}$. The Gaussian and MB distributions are characterized by the parameters listed in Table II. $\left[\mathrm{Cl}^{*}\right] /[\mathrm{Cl}]$ was $0.04 \pm 0.02$. These branching ratios did not change when the dose rate was increased from $2 \mathrm{~L}$ (corresponding to $1 \mathrm{ML}$ ) up to a few tens of langmuirs since multilayer formation of $\mathrm{HCl}$ does not occur. ${ }^{7}$

We have also examined the substrate temperature dependence of TOF spectra, which are shown in Fig. 6. PCI films were exposed with $\mathrm{HCl}(1 \mathrm{ML})$ at 100 and $140 \mathrm{~K}$. For the $140 \mathrm{~K}$ the substrate temperature was kept for a further $30 \mathrm{~min}$. Then, the substrate temperature was reduced to $100 \mathrm{~K}$ during TOF measurements. The TOF spectra are re- 
TABLE I. Contributions and translational temperatures of the Maxwell-Boltzmann (MB) components for the time-of-flight spectra of $\mathrm{H}$ atoms from ASW and PCI films at 193 and $157 \mathrm{~nm}$. Substrate temperature was kept at $100 \mathrm{~K} . \mathrm{ASW}=$ amorphous solid water. $\mathrm{PCI}=$ polycrystalline ice. Coverage of $\mathrm{HCl}$ was $1 \mathrm{ML}$.

\begin{tabular}{|c|c|c|c|c|}
\hline \multirow{2}{*}{$\begin{array}{l}\text { Dissociation } \\
\text { wavelength } \\
(\mathrm{nm})\end{array}$} & \multirow[b]{2}{*}{ Type of ice film } & \multicolumn{3}{|c|}{ Contribution of MB components (\%) } \\
\hline & & A $(2400 \pm 100 \mathrm{~K})$ & $\mathrm{B}(500 \pm 50 \mathrm{~K})$ & $\mathrm{C}(110 \pm 10 \mathrm{~K})$ \\
\hline \multirow[t]{4}{*}{193} & PCI without $\mathrm{HCl}$ & 100 & - & - \\
\hline & PCI with $\mathrm{HCl}$ & $47 \pm 7$ & $21 \pm 3$ & $32 \pm 10$ \\
\hline & ASW without $\mathrm{HCl}$ & $6 \pm 3$ & - & $94 \pm 3$ \\
\hline & ASW with $\mathrm{HCl}$ & $4 \pm 2$ & $2 \pm 2$ & $94 \pm 4$ \\
\hline \multirow{2}{*}{$\begin{array}{l}\text { Dissociation } \\
\text { wavelength } \\
(\mathrm{nm})\end{array}$} & & \multicolumn{3}{|c|}{ Contribution of MB components (\%) } \\
\hline & Type of ice film & A $(4750 \pm 250 \mathrm{~K})$ & B $(625 \pm 25 \mathrm{~K})$ & $\mathrm{C}(110 \pm 10 \mathrm{~K})$ \\
\hline \multirow[t]{2}{*}{157} & $\mathrm{PCI}$ with and without $\mathrm{HCl}$ & $41 \pm 3$ & $44 \pm 4$ & $15 \pm 5$ \\
\hline & ASW with and without $\mathrm{HCl}$ & $5 \pm 2$ & $12 \pm 2$ & $83 \pm 4$ \\
\hline
\end{tabular}

produced with the parameters listed in Table II. The TOF spectrum on the PCI film exposed with $\mathrm{HCl}$ at $140 \mathrm{~K}$ is essentially the same as that at $100 \mathrm{~K}$.

We investigated the formation of $\mathrm{Cl}$ and $\mathrm{Cl}^{*}$ atoms from the $193 \mathrm{~nm}$ photodissociation of the ice films dosed with $\mathrm{HCl}$, but could not detect the REMPI signals.

\section{DISCUSSION}

\section{A. Surface morphology changes probed by time-of-flight measurements of hydrogen atoms \\ 1. Origin of hydrogen atoms from the photodissociation of polycrystalline ice films}

In our previous experiments at $193 \mathrm{~nm}(6.4 \mathrm{eV})$, we have shown that the fast TOF component $\mathrm{A}$ from a neat PCI film comes from one-photon dissociation of the dimerlike water molecules on the topmost $\mathrm{H}_{2} \mathrm{O}$ layer of the ice film via reaction (1), which have photoabsorption near $200 \mathrm{~nm}$ due to the branched form of the water cluster. ${ }^{2,11}$ Similarly, Kimmel and Orlando reported threshold energies of $6.5-7.0 \mathrm{eV}$ for

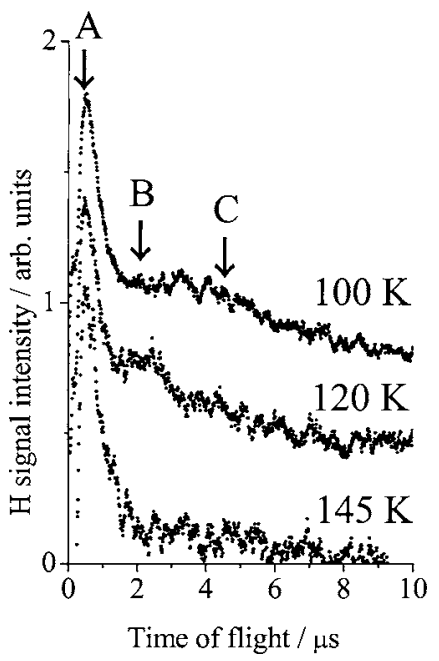

FIG. 4. Substrate temperature dependence of the TOF spectra of $\mathrm{H}$ atoms from the $193 \mathrm{~nm}$ photodissociation of polycrystalline ice films with $\mathrm{HCl}$ (1 ML). After the polycrystalline ice films were exposed to $\mathrm{HCl}$ at the indicated temperatures, TOF measurements were performed at $100 \mathrm{~K}$. A, B, and C stand for the Maxwell-Boltzmann translational components listed in Table I. desorption of $\mathrm{D}$ atoms following electron-beam irradiation on thin films of amorphous $\mathrm{D}_{2} \mathrm{O}$ ice. ${ }^{12}$ Hence, for the $193 \mathrm{~nm}$ photodissociation of the neat PCI film the TOF spectrum of the upper panel of Fig. 1 can be fitted solely by the fast component A. When an ASW film was photoirradiated at $193 \mathrm{~nm}$, however, the TOF spectrum consists mostly of the surface-accommodated slow component $\mathrm{C}$, as shown in the upper panel of Fig. 2. Since the adsorption of $\mathrm{HCl}$ induces disordering of the PCI film surface, the slow and middle components $\mathrm{C}$ and $\mathrm{B}$ appeared in the TOF spectrum, as shown in the lower panel of Fig. 1. Thus, the present TOF spectroscopy is specifically sensitive to disordering of the top surface. If the percentage of disordered surface area is proportional to that of the $\mathrm{B}$ and $\mathrm{C}$ components in TOF spec-

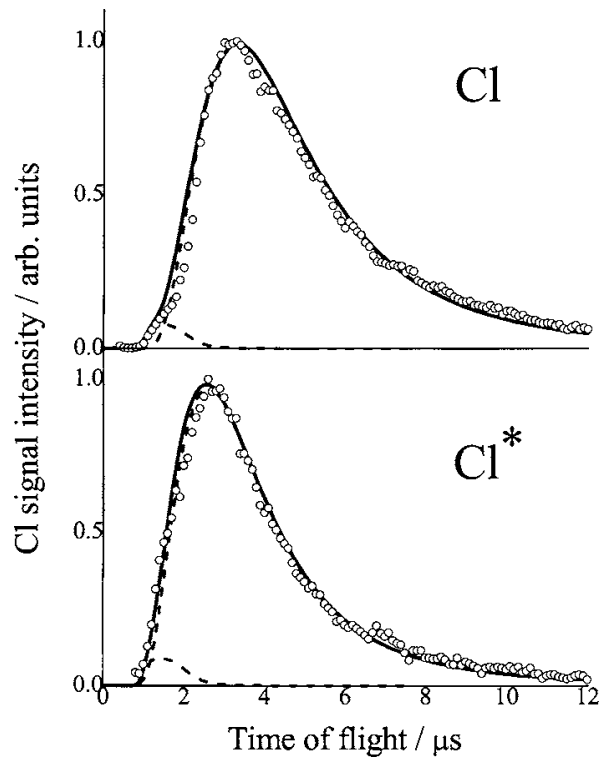

FIG. 5. TOF spectra of $\left.\mathrm{Cl}^{2}{ }^{2} P_{3 / 2}\right)$ and $\mathrm{Cl}^{*}\left({ }^{2} P_{1 / 2}\right)$ atoms from the $157 \mathrm{~nm}$ photodissociation of amorphous solid water films with $\mathrm{HCl}(1 \mathrm{ML})$ at $100 \mathrm{~K}$. The solid curves are fits to the data derived assuming the sum of a Gaussian distribution with $\left\langle E_{t}\right\rangle=1.40 \mathrm{eV}$ and a Maxwell-Boltzmann distribution with $T_{\text {trans }}=1700 \mathrm{~K}$ (upper panel), and a Gaussian distribution with $\left\langle E_{t}\right\rangle=1.40 \mathrm{eV}$ and a Maxwell-Boltzmann distribution with $T_{\text {trans }}=2800 \mathrm{~K}$ (lower panel). Contributions and translational energies (temperatures) are listed in Table II. 


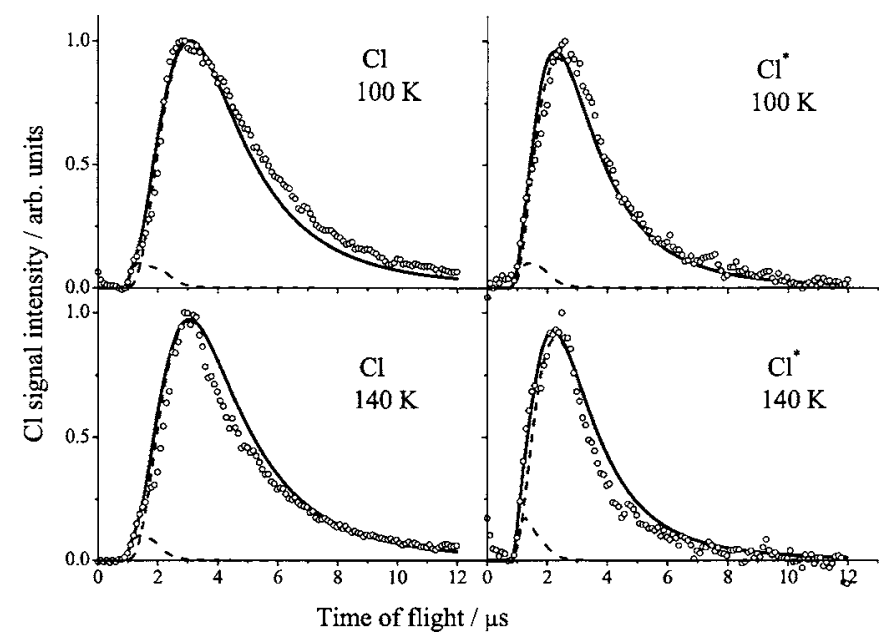

FIG. 6. TOF spectra of $\mathrm{Cl}$ and $\mathrm{Cl}^{*}$ from the $157 \mathrm{~nm}$ photodissociation of polycrystalline ice films with $\mathrm{HCl}(1 \mathrm{ML})$ at 100 and $140 \mathrm{~K}$. The solid curves are the sum of a Gaussian distribution and a Maxwell-Boltzmann distribution. Contributions and translational energies (temperatures) are listed in Table II.

tra, it is estimated to be $(53 \pm 13) \%$ at the ice temperature of $100 \mathrm{~K}$ upon $\mathrm{HCl}(1 \mathrm{ML})$ adsorption on a PCI film.

The photoabsorption spectrum of $\mathrm{HCl}$ adsorbed on a water ice film was calculated by Woittequand et al. using the Fourier transform of the autocorrelation function of a dissociative wave packet. ${ }^{13}$ The calculated absorption spectrum of molecular $\mathrm{HCl}$ on a PCI film at $0 \mathrm{~K}$ is blueshifted by $0.36 \mathrm{eV}$ with respect to the gas phase spectrum because of the surface stabilization in the ground state of molecular $\mathrm{HCl}$ attached to the ice surface. Hence, the $\mathrm{H}$ atoms from the photodissociation do not come from the $193 \mathrm{~nm}$ photodissociation of $\mathrm{HCl}$ adsorbed on the PCI surface. This blueshift was confirmed by the experimental results that $\mathrm{Cl}$ atoms were not detected in the $193 \mathrm{~nm}$ irradiation of the ice films dosed with $\mathrm{HCl}$, but observed at $157 \mathrm{~nm}$.

About the dissociation threshold wavelength, Kimmel and Orlando measured D atoms from the electron-stimulated dissociation (ESD) of amorphous $\mathrm{D}_{2} \mathrm{O}$ ice adsorbed on $\mathrm{Pt}(111)$ at $\sim 90 \mathrm{~K}^{12}$ They reported that a low energy threshold for $\mathrm{D}$ atom production is $6.5-7.0 \mathrm{eV}$. There exists the dissociative electronic state near $200 \mathrm{~nm}$. Their TOF spectra for $\mathrm{D}$ atoms consist of two components; one is ejected di- rectly from the surface without interacting to surrounding molecules, and the other is accommodated to the surface temperature prior to desorption. These results are in good agreement with the present TOF results. It is likely that the same electronic excitation and the dynamics occur in the photo- and electron bombardment dissociation.

The TOF spectrum at $157 \mathrm{~nm}(7.9 \mathrm{eV})$, the upper inset of Fig. 3, is characterized by summing the three MB distributions because of the bulk ice photodissociation, that is, the fast $\mathrm{H}$ atoms generated from the outmost surface correspond to component $\mathrm{A}^{\prime}$, the $\mathrm{H}$ atoms from the bulk phase correspond to component $\mathrm{B}^{\prime}$, and the translationally relaxed $\mathrm{H}$ atoms that are accommodated to the surface temperature correspond to component $\mathrm{C}^{2}$ Although molecular $\mathrm{HCl}$ has relatively strong photoabsorption at $157 \mathrm{~nm}$, the present TOF spectra with and without $\mathrm{HCl}$ in Fig. 3 are very similar to each other, because the population of molecular $\mathrm{HCl}$ on the ice surface at $100 \mathrm{~K}$ would be small with respect to water molecules in the bulk phase.

\section{Origin of hydrogen atoms from the photodissociation of amorphous solid water film}

The origin of the $\mathrm{H}$ atoms recorded at $193 \mathrm{~nm}$ from ASW is attributed to the photodissociation of surface species on ice films, while at $157 \mathrm{~nm}$ the $\mathrm{H}$ atoms come from the photodissociation of surface and bulk of ice films. ${ }^{2}$ Although the origins are different, the TOF spectra at 193 and $157 \mathrm{~nm}$ are both dominated by the slow component $\mathrm{C}$, indicating that the photofragment $\mathrm{H}$ atoms are accommodated to the substrate temperature by collisions in the micropores of the ASW film surfaces.

\section{B. Surface morphology change of water ice films on adsorption of hydrogen chloride}

In the TOF spectra of $\mathrm{H}$ atoms from the $193 \mathrm{~nm}$ photodissociation of the PCI film with $\mathrm{HCl}$ at 100, 120, and $140 \mathrm{~K}$, the signal intensity of component A was almost the same while slow components B and C appeared. The substrate temperature dependence of Fig. 4 shows that the components $\mathrm{B}$ and $\mathrm{C}$ gradually decreased from 100 to $120 \mathrm{~K}$. At $140 \mathrm{~K}$ these components were still present, and then disappeared at $145 \mathrm{~K}$. Dosing with $\mathrm{HCl}$ on the ice surface induced

TABLE II. Contribution and translational energies (temperatures) of the Gaussian and the Maxwell-Boltzmann (MB) components for the time-of-flight spectra of $\mathrm{Cl}^{2}\left({ }^{2} P_{3 / 2}\right)$ and $\mathrm{Cl}^{*}\left({ }^{2} P_{1 / 2}\right)$ atoms from the photodissociation of $\mathrm{HCl}$ on ASW and PCI films at $157 \mathrm{~nm}$. During the time-of-flight measurements the substrate temperature was kept at $100 \mathrm{~K}$. ASW=amorphous solid water. $\mathrm{PCI}=$ polycrystalline ice. Coverage of $\mathrm{HCl}$ was $1 \mathrm{ML}$.

\begin{tabular}{|c|c|c|c|c|c|c|}
\hline \multirow[b]{2}{*}{$\begin{array}{l}\text { Chlorine } \\
\text { atoms }\end{array}$} & \multirow[b]{2}{*}{$\begin{array}{l}\text { Adsorption } \\
\text { temperatures }\end{array}$} & \multirow[b]{2}{*}{$\begin{array}{l}\text { Ice film } \\
\text { with } \mathrm{HCl}\end{array}$} & \multicolumn{2}{|c|}{ Gaussian component } & \multicolumn{2}{|c|}{ MB component } \\
\hline & & & $\begin{array}{l}\text { Translational } \\
\text { energy }(\mathrm{eV})\end{array}$ & $\begin{array}{c}\text { Contribution } \\
(\%)\end{array}$ & $\begin{array}{c}\text { Translational } \\
\text { temperature }(\mathrm{K})\end{array}$ & $\begin{array}{c}\text { Contribution } \\
(\%)\end{array}$ \\
\hline $\mathrm{Cl}$ & 100 & ASW & $1.4 \pm 0.1$ & $2 \pm 1$ & $1700 \pm 100$ & $98 \pm 1$ \\
\hline $\mathrm{Cl}^{*}$ & & ASW & $1.4 \pm 0.1$ & $3 \pm 1$ & $2800 \pm 200$ & $97 \pm 1$ \\
\hline $\mathrm{Cl}$ & & PCI & $1.4 \pm 0.1$ & $3 \pm 1$ & $2000 \pm 200$ & $97 \pm 1$ \\
\hline $\mathrm{Cl}^{*}$ & & PCI & $1.4 \pm 0.1$ & $4 \pm 1$ & $3600 \pm 200$ & $96 \pm 1$ \\
\hline $\mathrm{Cl}$ & 140 & PCI & $1.4 \pm 0.1$ & $3 \pm 1$ & $2000 \pm 200$ & $97 \pm 1$ \\
\hline $\mathrm{Cl}^{*}$ & & PCI & $1.4 \pm 0.1$ & $7 \pm 2$ & $3600 \pm 200$ & $93 \pm 2$ \\
\hline
\end{tabular}


surface disordering below $140 \mathrm{~K}$ as discussed above. Adsorption states of $\mathrm{HCl}$ on water ice films were investigated by using the reactive ion scattering technique with $\mathrm{Cs}^{+}$as a function of ice temperature. ${ }^{3,7,14}$ This reactive ion scattering study suggests that for temperatures below $80 \mathrm{~K}$ molecular adsorption dominates, while the amount of ionic species increases until an ice temperature of $140 \mathrm{~K}$ is reached. ${ }^{3}$ This result shows that the ionic dissolution of molecular $\mathrm{HCl}$ on ice surfaces is completed around $140 \mathrm{~K}$. Therefore, components $\mathrm{B}$ and $\mathrm{C}$ disappeared in the present TOF spectrum of $\mathrm{H}$ atoms at $145 \mathrm{~K}$.

The TOF spectrum from the ASW film with $\mathrm{HCl}$ was not different from that without $\mathrm{HCl}$, because the surface morphology of the ASW film was effectively not changed by dosing with $\mathrm{HCl}$ (Fig. 2).

\section{Chlorine atoms from photodissociation of molecular $\mathrm{HCl}$ adsorbed on water ice films}

Since $\mathrm{HCl}$ are not completely ionized and molecular $\mathrm{HCl}$ remain on the ice surface even at $140 \mathrm{~K}, \mathrm{Cl}$ or $\mathrm{Cl}^{*}$ atoms were detected from the $157 \mathrm{~nm}$ photodissociation of $\mathrm{HCl}$ adsorbed on the PCI films (Figs. 5 and 6). Sadtchenko et al. ${ }^{15}$ reported in their temperature programmed desorption (TPD) experiments that there are three types of adsorption states at $95 \mathrm{~K}, \alpha-\beta$-, and $\sigma$-HCl. $\alpha-\mathrm{HCl}$ was attributed either to molecular $\mathrm{HCl}$ adsorbed on the surface of $\mathrm{HCl}$ hexahydrate ${ }^{16}$ or to a thin $\mathrm{HCl}$-monolayer adlayer formed on the saturated hexahydrate film. ${ }^{17} \beta$ - $\mathrm{HCl}$ mainly exists on an ASW film. $\sigma-\mathrm{HCl}$ is characteristic of the PCI surface and is essentially absent at the ASW surface. Table II shows that the translational temperatures of the MB components of chlorine atoms from the photodissociation of molecular $\mathrm{HCl}$ on the PCI film are higher than those from the ASW films. The translational temperature difference between the PCI and ASW films might be due to the different populations of three adsorption states, $\sigma-\mathrm{HCl}$ for PCI and $\beta-\mathrm{HCl}$ for ASW.

The branching ratios of $\mathrm{Cl}^{*} / \mathrm{Cl}$ from the gas phase photodissociation at $157 \mathrm{~nm}$ were experimentally and theoretically obtained to be $0.81 \pm 0.09$ and $\sim 0.67$, respectively. ${ }^{18,19}$ The present ratios of $\mathrm{Cl}^{*} / \mathrm{Cl}(=0.04-0.08)$ from the ice film surface are low because (a) the potential surface distortion changes the transmission probabilities in the potential intersection regions, and (b) the slow velocity of the photofragment results in adiabatic behavior of the dissociation potentials.

\section{Molecular states of $\mathrm{HCl}$ on water ice films}

Depending on the surface temperature, $\mathrm{HCl}$ on ice form mono-, tri-, and hexahydrate, or is ionized. ${ }^{20}$ As shown in Fig. 7, there are numerous reports of studies on the interactions of $\mathrm{HCl}$ with ice films with various experimental methods: temperature-programed desorption mass spectrometry (TPDMS), ${ }^{15}$ infrared spectroscopy, ${ }^{17,21,22}$ secondary ion mass spectroscopy, ${ }^{10,23,24}$ laser thermal desorption, ${ }^{25}$ reactive ion scattering (RIS), ${ }^{3,7,14}$ near-edge x-ray absorption fine structures (NEXAFSs), ${ }^{26}$ electron-stimulated desorption, ${ }^{27}$ and molecular beam scattering techniques. ${ }^{28,29}$

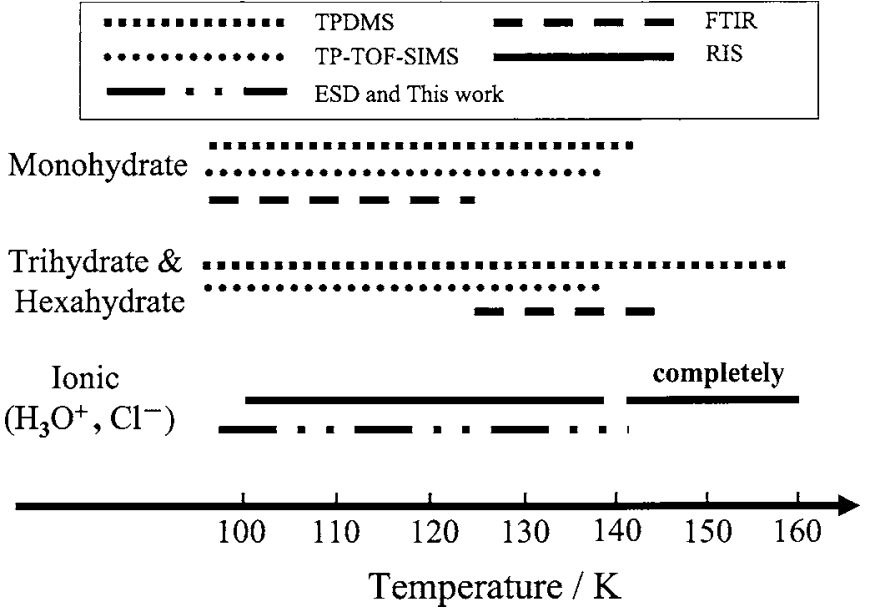

FIG. 7. Molecular adsorption states of $\mathrm{HCl}$ of water ice films from references. Temperature-programed desorption mass spectrometry (TPDMS), Ref. 15; temperature-programed time-of-flight secondary-ion mass spectrometry (TP-TPF-SIMS), Ref. 10; electron-stimulated desorption (ESD), Ref. 27; Fourier transform infrared spectroscopy (FTIR), Ref. 21; and reactive ion scattering (RIS), Refs. 7 and 14.

The RIS study suggests that for temperatures below $80 \mathrm{~K}$ molecular adsorption dominates, while the amount of ionic species increases until an ice temperature of $140 \mathrm{~K}$ is reached. ${ }^{3}$ These results are corroborated by the $\mathrm{H}-\mathrm{Cl}$ bond signal in photostimulated desorption-NEXAFS spectra. At $150 \mathrm{~K}$, this bond is only visible for pure $\mathrm{HCl}$, but not for $\mathrm{HCl}$ adsorbed on ice films, which directly demonstrates the dissociation of $\mathrm{HCl}$. Foster et al. investigated the interaction of $\mathrm{HCl}$ with ice surfaces as a function of ice temperature, using laser-induced thermal desorption techniques. ${ }^{25}$ In agreement with the $\mathrm{HCl} \cdot \mathrm{H}_{2} \mathrm{O}$ phase diagram, a stable $\mathrm{HCl} \cdot 3 \mathrm{H}_{2} \mathrm{O}$ trihydrate consistently formed between 140 and 148 K. Monte Carlo simulations by Devlin et al. suggested that a minimum of three hydrogen bonds is needed for $\mathrm{HCl}$ ionization. $^{22}$ These results show that the ionic dissociation of $\mathrm{HCl}$ on ice surfaces is completed between 140 and $150 \mathrm{~K}$, as shown in Fig. 7. Therefore, in the present experiment, components $\mathrm{B}$ and $\mathrm{C}$ disappeared in the TOF spectrum of $\mathrm{H}$ atoms at $145 \mathrm{~K}$ (Fig. 4).

\section{CONCLUSION}

The time-of-flight spectrum of hydrogen atoms from the $193 \mathrm{~nm}$ photodissociation of surface water molecules on polycrystalline ice films at $100 \mathrm{~K}$ after dosing with $\mathrm{HCl}(1$ ML) is characterized by a combination of three different (fast, medium, and slow) Maxwell-Boltzmann energy distributions, while the spectrum measured without dosing of $\mathrm{HCl}$ is fitted solely by the fast component. The appearance of the slow components is attributed to partial disordering of the ice film surface by dosing with $\mathrm{HCl}$. When the ice film temperature was raised to $145 \mathrm{~K}$ the medium and slow components did not appear even after dosing with $\mathrm{HCl}$ because the surface morphology was kept of polycrystalline structure. The fact that detection of chlorine atoms in the ${ }^{2} P_{3 / 2}$ and ${ }^{2} P_{1 / 2}$ levels was successful from the $157 \mathrm{~nm}$ photodissociation of 
molecular $\mathrm{HCl}$ on the ice films dosed by $\mathrm{HCl}$ at $100-140 \mathrm{~K}$ suggests that molecular $\mathrm{HCl}$ remain partially on the surface up for $100-140 \mathrm{~K}$.

${ }^{1}$ V. F. McNeill, T. Loerting, F. M. Geiger, B. L. Trout, and M. J. Molina, Proc. Natl. Acad. Sci. U.S.A. 103, 9422 (2006).

${ }^{2}$ A. Yabushita, D. Kanda, N. Kawanaka, M. Kawasaki, and M. N. R. Ashfold, J. Chem. Phys. 125, 133406 (2006).

${ }^{3}$ H. Kang, T.-H. Shin, S.-C. Park, I. K. Kim, and S.-J. Han, J. Am. Chem. Soc. 122, 9842 (2000).

${ }^{4}$ A. Yabushita, Y. Inoue, T. Senga, M. Kawasaki, and S. Sato, J. Phys. Chem. B 106, 3151 (2002)

${ }^{5}$ M. Kawasaki, Appl. Surf. Sci. 135, 1159 (1998).

${ }^{6}$ S. Sato, D. Yamaguchi, K. Nakagawa, Y. Inoue, A. Yabushita, and M. Kawasaki, Langmuir 16, 9533 (2000).

${ }^{7}$ S.-C. Park and H. Kang, J. Phys. Chem. B 109, 5124 (2005).

${ }^{8}$ P. M. Regan, S. R. Langford, D. Ascenzi, P. A. Cook, A. J. Orr-Ewing, and M. N. R. Ashfold, Phys. Chem. Chem. Phys. 1, 3247 (1999).

${ }^{9}$ F. M. Zimmermann and W. Ho, Surf. Sci. Rep. 22, 127 (1995).

${ }^{10}$ M. Kondo, H. Kawanowa, Y. Gotoh, and R. Souda, Surf. Sci. 594, 141 (2005).

${ }^{11}$ A. Yabushita, Y. Hashikawa, A. Ikeda, M. Kawasaki, and H. Tachikawa, J. Chem. Phys. 120, 5463 (2004)

${ }^{12}$ G. A. Kimmel and T. M. Orlando, Phys. Rev. Lett. 75, 2606 (1995).

${ }^{13}$ S. Woittequand, C. Toubin, B. Pouilly, M. Monnerville, S. Briquez, and H.-D. Meyer, Chem. Phys. Lett. 406, 202 (2005).
${ }^{14}$ H. Kang, Acc. Chem. Res. 38, 893 (2005).

${ }^{15}$ V. Sadtchenko, C. F. Giese, and W. R. Gentry, J. Phys. Chem. B 104, 9421 (2000).

${ }^{16}$ J. D. Graham and J. T. Roberts, J. Phys. Chem. 89, 5974 (1994).

${ }^{17}$ S. F. Banham, J. R. Sodeau, A. B. Horn, M. R. S. McCoustra, and M. A. Chesters, J. Vac. Sci. Technol. A 14, 1620 (1996).

${ }^{18}$ K. Tonokura, Y. Matsumi, M. Kawasaki, S. Tasaki, and R. Bersohn, J. Chem. Phys. 97, 8210 (1992).

${ }^{19}$ P. M. Regan, D. Ascenzi, A. Brown, G. G. Balint-Kurti, and A. J. OrrEwing, J. Chem. Phys. 112, 10259 (2000).

${ }^{20}$ T. Huthwelker, M. Ammann, and T. Peter, Chem. Rev. (Washington, D.C.) 106,1375 (2006).

${ }^{21}$ S. Haq, J. Harnett, and A. Hodgson, J. Phys. Chem. B 106, 3950 (2002).

${ }^{22}$ J. P. Devlin, N. Uras, J. Sadlej, and V. Buch, Nature (London) 487, 269 (2002).

${ }^{23}$ H. A. Donsig and J. C. Vickerman, J. Chem. Soc., Faraday Trans. 93, 2755 (1997)

${ }^{24}$ M. Kondo, H. Kawanowa, Y. Gotoh, and R. Souda, J. Chem. Phys. 121, 8586 (2004).

${ }^{25}$ K. L. Foster, M. A. Tolbert, and S. M. George, J. Phys. Chem. A 101, 4979 (1997).

${ }^{26}$ P. Parent and C. Laffon, J. Phys. Chem. B 109, 1547 (2005).

${ }^{27}$ J. Herring, A. Aleksandrov, and T. M. Orlando, Phys. Rev. Lett. 92, 187602 (2004).

${ }^{28}$ M. J. Isakson and G. O. Sitz, J. Phys. Chem. A 103, 2044 (1999).

${ }^{29}$ J. Harnett, S. Haq, and A. Hodgson, Surf. Sci. 532, 478 (2003). 